\title{
ESTUDO COMPARATIVO DO CICLO EVOLUTIVO DE RHODNIUS NEGLECTUS ALIMENTADOS EM POMBOS OU CAMUNDONGOS.
}

\author{
Liléia Diotaiuti e João Carlos Pinto Dias
}

\begin{abstract}
Baseados no encontro de $77,2 \%$ de reação de precipitina positiva para soro antiave de R. neglectus capturados em palmeiras da periferia de Belo Horizonte, estudamos o ciclo evolutivo de uma colonia recém-estabelecida no laboratório alimentada com sangue de pombo ou camundongo, na expectativa de demonstrarmos maior adaptação deste triatomineo ao sangue da ave. Para comparação, estudamos o ciclo evolutivo destes insetos numa colónia há muito mantida em insetário.

Nossos resultados mostram um desenvolvimento mais rápido da colónia recémestabelecida, assim como do lote de triatomíneos alimentado em camundongo. Esses achados sugerem menor potencial biológico para triatomineos criados por longo tempo em insetário em comparação a novas colônias. Sendo as aves os principais habitantes das palmeiras, a aparente preferência alimentar por sangue de aves demonstrada pela reação de precipitina parece ser circunstancial e não seletiva na busca do sangue com o qual o triatomineo obteria melhor desenvolvimento.
\end{abstract}

Palavras chave: Triatomineos. Rhodnius neglectus. Ciclo evolutivo. Preferência alimentar.

Nos últimos anos, espécies de triatomineos até hoje considerados secundários na epidemiologia da doença de Chagas têm mostrado maior ou menor capacidade de colonização das casas em várias regiões brasileiras. É de se considerar a importância do Triatoma pseudomaculata no Nordeste, do Triatoma vitticeps no Espírito Santo, do Panstrongylus megistus em Minas Gerais e Goiás, e do Triatoma sordida no Mato Grosso e Minas Gerais ${ }^{12}$.

O Rhodnius neglectus é uma espécie de larga dispersão no país, já tendo sido capturado no ambiente peri e/ou intradomiciliar em 11 Estados ${ }^{12}$. Marcadamente é uma espécie de hábitos silvestres, cujo écotopo natural são palmeiras de várias espécies ${ }^{3}$. $O$ achado de suas colônias no peridomicílio ocorre com relativa frequiência. No periodo de 1975 a 1979 , Castro Filho e Silveira, relataram a captura de $\mathbf{3 . 0 7 5}$ exemplares daquela espécie no trabalho de rotina da SUCAM $^{4}$ o que a coloca no sétimo lugar em número absoluto entre as espécies encontradas no período. Foi portanto uma surpresa quando, só no Estado de Goiás, no periodo de 1975 a 1982 , Silveira e cols ${ }^{11}$ encontraram 5.367 exemplares, sendo 4.945 nos anos de 1980 , 1981 e 1982, utilizando-se a mesma metodologia do trabalho de 1979 , com $43,1 \%$ de municipios apresen-

Centro de Pesquisa René Rachou - Caixa Postal 1743 30190 Belo Horizonte - SUCAM, Ministério da Saúde Divisão de Doença de Chagas - Brasilia/DF. Auxílio parcial do CNPq.

Recebido para publicação em 11/8/1986 tando colônias intradomiciliares desta espécie. Achados deste tipo vêm indicando a necessidade de estudos que visem o esclarecimento do potencial vetorial desta espécie, principalmente diante da perspectiva de total erradicação do Triatoma infestans nos próximos anos, através do uso sistemático de inseticidas pela SUCAM.

Em pesquisa anterior, tivemos a oportunidade de estudar o Rhodnius neglectus em seu ecótopo natural na periferia de Belo Horizonte, área em que este triatomíneo encontra-se restrito ao seu ambiente natural (palmeiras de macaúba), só esporadicamente sendo encontrado em ecótopos artificiais 7 . O índice global de infecção pelo Trypanosoma cruzi foi relevante $(15,9 \%)$, demonstrando a sua importância na manutenção do ciclo silvestre deste parasita. $O$ estudo do hábito alimentar, através da reação de precipitina, apresentou uma positividade de $77,2 \%$ para sangue de ave. Estes achados concordam com os de outros pesquisadores, que nunca encontraram menos de $50 \%$ de triatomíneos desta espécie, capturados em palmeiras, com sangue de ave no seu tubo digestivo ${ }^{12} 3$. Estes dados sugerem, portanto, que o Rhodnius neglectus apresenta preferência alimentar para este grupo de animais.

A partir destas informações, pretendíamos com este trabalho testar o desenvolvimento biológico de uma colônia de Rhodnius neglectus recentemente capturados no campo quando submetidos a oferta de dois tipos de sangue, e definir o conceito "preferência alimentar" para esta espécie. Para comparação, pro- 
curamos estudar o ciclo biológico destes insetos em colônia já há muito adaptada ao laboratório.

\section{MATERIAL E MÉTODOS}

Nestes experimentos foram utilizados duas colônias de Rhodnius neglectus: uma procedente de Ribeirão Preto (colônia Ribeirão Preto), e mantida em insetário há vários anos com alimentação exclusivamente em aves, e/ou outra, procedente da Fazenda Sumidouro (colônia Sumidouro), municipio de Caeté, MG, desenvolvida a partir de exemplares recentemente capturados em palmeiras de macaúba. Os insetos foram mantidos em insetário semiclimatizado, à temperatura de $27 \pm 2{ }^{\circ} \mathrm{C}$ e $70 \%$ de umidade, e alimentação quinzenal.

\section{a) Ciclo biológico: colônia Sumidouro e colônia Ribeirão Preto}

A fim de estudarmos o potencial de desenvolvimento da colônia recém-estabelecida em nosso insetário, montamos um experimento para comparar o seu tempo de evolução (ovo - adulto), mortalidade e oviposição com a colônia Ribeirão Preto. Foram utilizados 30 ovos de cada procedência, coletados no mesmo periodo, e colocados individualmente $\mathrm{em}$ frascos de vidro com $5 \mathrm{~cm}$ de diâmetro por $9,5 \mathrm{~cm}$ de altura. Acompanhou-se o desenvolvimento dos triatomíneos anotando-se a data da eclosão dos ovos e o dia em que se efetuava cada muda até o estádio adulto.

Oviposição: ao final deste experimento, foi formado ao acaso o maior número possivel de casais de cada coleção para observação da média de ovos colocados por fêmea. Os ovos eram retirados semanalmente dos frascos e contados.

b) Colônia Sumidouro: desenvolvimento biológico de lotes alimentados em ave ou camundongo.

Foram separados 60 ovos da colônia Sumidouro, observados individualmente em frascos semelhantes ao do experimento anterior. Estabeleceu-se que 30 ninfas recém-eclodidas passariam a ser alimentadas apenas em camundongos anestesiados com "Nembutal" pela via intraperitoneal, enquanto as outras 30 seriam alimentadas em pombos. Como no experimento anterior já havia sido determinado o período de incubação dos ovos, nesse só foram anotadas as datas das mudas das ninfas desde o 1 . estágio até adultos. A alimentação das duas coleções era concomitante, $\mathrm{e} o$ alimento oferecido por um prazo máximo de quatro horas.

Oviposição: observada como no experimento anterior, porém com o esquema de alimentação acima descrito.

\section{RESULTADOS}

a) Ciclo biológico: colônia Sumidouro e colônia Ribeirão Preto.

A análise individual dos vários estádios evolutivos das duas colônias indicou uma certa variação no tempo de evolução dos triatomineos, ora uma colônia apresentando um desenvolvimento mais rápido, ora a outra (Tabela 1). Porém, a análise geral do experimento, tomando-se para observação oito pares de

Tabela 1 - Duração média dos vários estádios evolutivos e mortalidade de duas colônias de R. neglectusRibeirão Preto e Sumidouro - mantidas em laboratório.

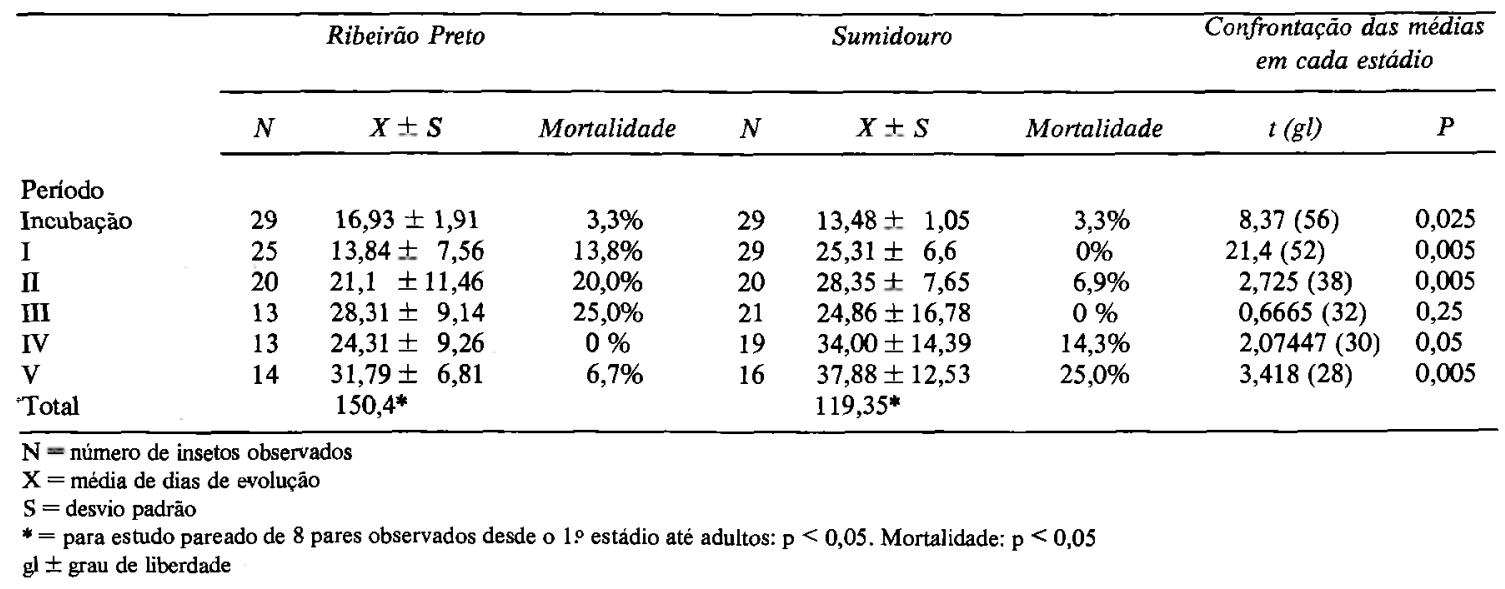


Diotaiuti L, Dias JCP. Estudo comparativo do ciclo evolutivo de Rhodnius neglectus alimentados em pombos ou camundongos. Revista da Sociedade Brasileira de Medicina Tropical 20: 95-100, Abr-Jun, 1987.

triatomíneos que participaram no experimento desde o 10 estádio até adultos, na medida em que vários insetos morreram no seu transcurso, mostrou que a colônia recém-vinda do campo (colônia Sumidouro) apresentava um desenvolvimento significativamente mais rápido que a colônia estabelecida no insetário há mais tempo (colônia Ribeirāo Preto).

Os índices gerais de mortalidade não demonstraram diferença significativa entre as duas colônias.

Oviposicão: Não houve diferença significativa entre as posturas médias das fèmeas das diferentes colônias (Tabela 2).

\section{b) Colônia Sumidouro: desenvolvimento biológico de lotes alimentados em ave ou camundongo}

Da mesma forma que o experimento anterior, a análise dos vários estádios evolutivos nos dois grupos de triatomineos apresentou uma certa variação no tempo de evolução, tendo sido significativamente mais rápida em oito pares observados desde o $1 \%$ estádio até adultos, no grupo alimentado em camundongo (Tabela 3). Também neste experimento os índices gerais de mortalidade não mostraram diferenças significativas entre os dois grupos.

Oviposição: a postura média das fềmeas alimentadas em aves ou camundongos apresentou uma diferença significativa entre os dois grupos, tendo sido maior no grupo alimentado em camundongo $(1,8$ ovos/dia) que em ave (0,5 ovo/dia) (Tabela 4).

\section{DISCUSSÃO}

Já é sabido pelos criadores de triatomíneos que a introdução periódica de exemplares recém-capturados no campo em colônias há muito tempo mantidas

Tabela 2 - Posturas médias das colônias de R. neglectus provenientes de Ribeirão Preto e da Fazendá Sumidouro

\begin{tabular}{|c|c|c|c|c|c|c|c|}
\hline \multirow[b]{2}{*}{$\begin{array}{l}\text { No de } \\
\text { Fêmeas }\end{array}$} & \multicolumn{3}{|c|}{ Ribeirão Preto } & \multicolumn{4}{|c|}{ Sumidouro } \\
\hline & $\begin{array}{l}\text { Tempo de } \\
\text { Observação }\end{array}$ & $\begin{array}{l}\text { Total de } \\
\text { Ovos Postos }\end{array}$ & $\begin{array}{l}\text { Média Diária } \\
\text { de Ovos/fêmea }\end{array}$ & $\begin{array}{l}\text { No de } \\
\text { Fêmeas }\end{array}$ & $\begin{array}{l}\text { Tempo de } \\
\text { Observação }\end{array}$ & $\begin{array}{c}\text { Total de } \\
\text { Ovos Postos }\end{array}$ & $\begin{array}{c}\text { Média Diária de } \\
\text { Ovos/fêmea }\end{array}$ \\
\hline 7 & 48 dias & 310 & 0,9 & 7 & 46 dias & 109 & 0,3 \\
\hline 11 & 33 dias & 404 & 1,1 & 8 & 2 dias & 16 & 1,0 \\
\hline 10 & 10 dias & 158 & 1,6 & 11 & 47 dias & 739 & 1,4 \\
\hline 8 & 8 dias & 112 & 1,8 & 10 & 14 dias & 427 & 3,1 \\
\hline \multicolumn{7}{|c|}{$X=1,4 \pm 0,42$} & $X=1,5 \pm 1,19$ \\
\hline
\end{tabular}

Tabela 3 - Duração média dos vários estádios evolutivos e mortalidade de R. neglectus - Colonia Sumidouro - alimentados somente em aves ou camundongos

\begin{tabular}{|c|c|c|c|c|c|c|c|c|}
\hline & \multicolumn{3}{|c|}{ Alimentação em ave } & \multicolumn{3}{|c|}{ Alimentação em camundongo } & \multicolumn{2}{|c|}{$\begin{array}{c}\text { Confrontação das médias } \\
\text { em cada estádio }\end{array}$} \\
\hline & $N$ & $X \pm \mathrm{S}$ & Mortalidade & $N$ & $X \pm S$ & Mortalidade & $T(g l)$ & $P$ \\
\hline$I$ & 27 & $20,67 \pm 6,39$ & $0 \%$ & 24 & $21,58 \pm 9,69$ & $17,2 \%$ & $0,393(49)$ & 0,30 \\
\hline II & 24 & $20,17 \pm 6,44$ & $7,4 \%$ & 23 & $34,69 \pm 43,59$ & $0 \%$ & $1,5789(45)$ & 0,05 \\
\hline III & 22 & $18,05 \pm 9,21$ & $9,1 \%$ & 23 & $26,69 \pm 13,07$ & $0 \%$ & $2,4957(43)$ & 0,01 \\
\hline IV & 21 & $39,86 \pm 25,02$ & $0 \%$ & 21 & $28,62 \pm 11,75$ & $4,3 \%$ & $1,818(40)$ & 0,05 \\
\hline $\mathrm{V}$ & 15 & $79,80 \pm 40,89$ & $28,6 \%$ & 20 & $51,45 \pm 18,63$ & $4,8 \%$ & $2,664(33)$ & 0,01 \\
\hline Total & & $190,6^{*}$ & & & $150,3^{*}$ & & & \\
\hline
\end{tabular}

\footnotetext{
$\mathrm{N}=$ número de insetos observados

$\mathrm{X}=$ média de dias de evoluçăo

$\mathrm{S}=$ desvio padräo

* = para estudo pareado de 9 pares observados desde o 1.0 estádio ate adultos: $\mathrm{p}<0,10$. Mortalidade: $\mathrm{p}<0,05$

gl = graus de liberdade
} 
Diotaiuti L, Dias JCP. Estudo comparativo do ciclo evolutivo de Rhodnius neglectus alimentados em pombos ou camundongos. Revista da Sociedade Brasileira de Medicina Tropical 20: 95-100, Abr-Jun, 1987.

Tabela 4 - Posturas médias da colônia de $\mathrm{R}$. neglectus provenientes da Fazenda Sumidouro submetida à alimen. tação em ave ou camundongo.

\begin{tabular}{|c|c|c|c|c|c|c|c|}
\hline \multirow[b]{2}{*}{ NoFêmeas } & \multicolumn{3}{|c|}{ Ave } & \multirow[b]{2}{*}{$\begin{array}{l}\text { No de } \\
\text { Fêmeas }\end{array}$} & \multicolumn{3}{|c|}{ Camundongo } \\
\hline & $\begin{array}{l}\text { Duração da } \\
\text { Ovoposiçấo }\end{array}$ & $\begin{array}{c}\text { Total de } \\
\text { Ovos Postos }\end{array}$ & $\begin{array}{c}\text { Média diária } \\
\text { de Ovos/fêmea }\end{array}$ & & $\begin{array}{l}\text { Duraçāo da } \\
\text { Ovoposição }\end{array}$ & $\begin{array}{c}\text { Total de } \\
\text { Ovos Postos }\end{array}$ & $\begin{array}{l}\text { Média Diária } \\
\text { de Ovos/fêmea }\end{array}$ \\
\hline 4 & 21 dias & 18 & 0,2 & 8 & 21 dias & 228 & 1,4 \\
\hline 5 & 55 dias & 261 & 1,0 & 10 & 6 dias & 113 & 1,9 \\
\hline 4 & 3 dias & 11 & 0,3 & 8 & 51 dias & 879 & 2,2 \\
\hline$P<0,05$ & & & $X=0,50 \pm 0,44$ & & & & $X=1,83 \pm 0,4$ \\
\hline
\end{tabular}

em insetário é capaz de recuperar o potencial biológico de algumas espécies, que com o tempo, passam a produzir exemplares com sinal de degeneração genética, possivelmente induzida pelos retrocrųamentos sucessivos impostos pelo confinamento. Portanto, não foi uma surpresa a observação de que a colônia Sumidouro, recém-estabelecida em nosso insetário, tivesse um desenvolvimento mais rápido que a antiga colônia Ribeirão Preto, numa demonstração de superioridade de performance biológica, e boa adaptação às novas condições, observada também pela taxa de mortalidade, não diferente da apresentada pela criação paulista.

O ciclo evolutivo do $R$. neglectus é dos mais rápidos entre as espécies de triatomineos, podendo-se, teoricamente, obter até três gerações desse inseto em um ano. No seu ecótopo natural (palmeiras), observou-se a formação de pelo menos dois picos de adultos no periodo de 12 meses $^{7}$, considerando-se aqui as adversidades que o $R$. neglectus deve enfrentar que cerceiam o seu pleno desenvolvimento no campo. Dias ${ }^{6}$, em condições naturais e alimentação semanal em frangos, obteve adultos no prazo de 90 a 181 dias. Freitas e cols ${ }^{8}$ demonstraram que os intervalos entre os repastos interferem de maneira a se fechar o ciclo mais rapidamente quando a alimentação é semanal (média de 85,9 dias) em comparação com a alimentação quinzenal (média de 96,7 dias), sob condições controladas $\left(26^{\circ} \mathrm{C} 70 \%\right.$ de umidade). No entanto, mesmo com alimentação assegurada no laboratório, observamos uma grande variação individual no tempo de evolução, que concorda com os demais relatos da literatura 68 .

O lote de triatomíneos alimentados em camundongo apresentou um resultado significativamente mais rápido que o alimentado em pombos. Corrêa ${ }^{5}$, trabalhando com $T$. infestans alimentados em três diferentes animais (galinhas, gambá e cão), observou o melhor tempo de evolução no lote cujo repasto foi sempre executado em cão, o que nos parece, poderia sugerir uma maior adaptação deste inseto a esta fonte alimentar, reforçando a idéia da domesticidade desta espécie. Jirón e Zeledón ${ }^{9}$ ofereceram quatro diferentes fontes de alimentação (cão, galinha, gambá e sapo) para lotes de $T$. infestans, $T$. dimidiata e $R$. prolixus. Observaram que durante o dia, maior número de exemplares de $T$. infestans sugaram cão, tendo sido o sapo a espécie menos procurada. Mesmo assim excetuando-se o caso do sapo, consideraram que não se pode afirmar que tenha havido "uma preferência alimentar clara ou marcada, mas que o tipo e comportamento dos hospedeiros é que vai determinar a atividade alimentar dos insetos", tendo sido sugados mais freqüentemente os animais que dormiam neste período. Gostariamos, no entanto, de ressaltar que os camundongos por nós utilizados eram anestesiados e os pombos imobilizados.

Nossa amostragem é pequena para que possamos afirmar haja maior adaptação do $R$. neglectus ao sangue de camundongo, do que ao sangue de ave. Por outro lado, os dados reforçam a idéia de que a preferência alimentar do $R$. neglectus no seu ecótopo natural seja circunstancial, e não seletiva por tipo de sangue, conforme sugerido por Minter ${ }^{10}$ para os triatomíneos em geral. Prova disto foi a verificação no trabalho anterior de um número significativo (12/132) de insetos alimentados com sangue de anfibios no ambiente natural, em contraste com a menor escolha de sapo pelos triatomíneos no experimento de Jirón \& Zeledón ${ }^{9}$. Resta assinalar que na referida observação, praticamente em todas as palmeiras dissecadas apresentaram-se pequenos anfibios (principalmente $\mathrm{Hyla}$ fuscovaria), assim mostrando uma boa oferta deste tipo de sangue as colônias de $R$. neglectus ${ }^{7}$.

\section{SUMMARY}

Feeding patterns of $\mathbf{R}$. neglectus collected in palm trees around Belo Horizonte (Minas Gerais, Brazil) were investigated. Precipitin tests showed 
Diotaiuti L, Dias JCP. Estudo comparativo do ciclo evolutivo de Rhodnius neglectus alimentados em pombos ou camundongos. Revista da Sociedade Brasileira de Medicina Tropical 20: 95-100, Abr-Jun, 1987.

$77.2 \%$ of avian blood. In view of these results, a new colony of $\mathbf{R}$. neglectus established in the laboratory was fed regularly on pigeons or mice, in order to verify a possible better adaptation of this insect to the avian blood. As a control group a colony of $\mathbf{R}$. neglectus which has been maintained for several years in the laboratory was also observed.

The results show a better development of the "new" colony in comparison with the old one, and of those bugs nourished with mice blood. Such findings suggest a poorer biological potential for triatomines maintained for long time in artificial conditions, in comparison with those living in the natural environment. As birds are the main vertebrate inhabitants of palm trees (the natural ecotope of $\mathrm{R}$. neglectus), the apparent feeding preference of this species for avian blood seems to be merely circumstancial and not related to a better biological performance provided by this kind of blood.

Key words: Triatominae. Rhodnius neglectus. Evolutive cycle. Feeding preference.

\section{REFERÊNCIAS BIBLIOGRÁFICAS}

1. Barbosa MDM. Aspectos ecológicos do ciclo evolutivo do Trypanosoma cruzi em região de cerrado (Município de Formosa, Estado de Goiás). Tese de Doutoramento. Universidade de São Paulo, São Paulo, 1980.

2. Barreto MP, Siqueira AF,Ferriolli Filho F, Carvalheiro JR. Estudo sobre reservatórios e vetores silvestres do Trypanosoma cruzi. XI - Observaçōes sobre um foco natural da tripanossomose americana no município de Ribeirão Preto, SP. Revista do Instituto de Medicina Tropical de São Paulo 8:103-112, 1966.

3. Barreto MP, Albuquerque RDR, Funayama GK. Estudos sobre reservatórios e vetores silvestres do Trypano- soma cruzi. XXXVI - Investigações sobre triatomíneos de palmeiras no município de Uberaba, MG, Brasil. Revista Brasileira de Biologia 8:577-588, 1969.

4. Castro Filho J, Silveira AC. Distribuição da doença de Chagas no Brasil. Revista Brasileira de Malariologia e Doenças Tropicais 31: 85-98, 1979.

5. Corrèa FAOMA. Estudo comparativo do ciclo evolutivo do Triatoma infestans Klug, 1834 alimentado em diferentes animais. Tese de Doutoramento. Faculdade de Medicina de Ribeirão Preto, USP, 1961.

6. Dias E. Notas sobre o tempo de evolução de algumas espécies de triatomíneos em laboratório. Revista Brasileira de Biologia 15:157-158, 1955.

7. Diotaiuti L, Dias JCP. Ocorrência e biologia do Rhodnius neglectus Lent, 1954 em macaubeiras da periferia de Belo Horizonte, MG. Memórias do Instituto Oswaldo Cruz 79:293-301, 1984.

8. Freitas MG, Costa JO, Costa HMA. Alguns aspectos da biologia do Rhodnius neglectus Lent, 1954 (Hemiptera, Triatominae) em condições de laboratório. I - Evolução. Arquivos da Escola de Veterinária 19:81-87, 1967.

9. Jirón LF, Zeledón R. Preferencias alimentares de tres espécies de Triatominae (Hemiptera, Reduviidae). en condiciones experimentales. Revista Biologia Tropical 30:151-159, 1982.

10. Minter DM. Triatominae bugs and the household ecology of Chagas' disease. Medical Entomology Centenary Symposium Proceedings, Royal Society of Tropical Medicine and Hygiene 85-93, 1977.

11. Silveira AC, Diotaiuti L, Neiva E, Matos CAS, Elias M. Domiciliação de Rhodnius neglectus Lent, 1954 no Estado de Goiás, Brasil. In: Resumos da X Reunião de Pesquisa Básica da Doença de Chagas, Caxambu, V 16, 1983.

12. Silveira AC, Feitosa VR, Borges R. Distribuição de Triatomíneos capturados no ambiente domiciliar, no periodo de 1975/1983, Brasil. Revista de Malariologia e Doenças Tropicais 36:15-312, 1984. 